Çukurova Üniversitesi Mühendislik Mimarlık Fakültesi Dergisi, 32(4), ss. 135-146, Aralık 2017

Çukurova University Journal of the Faculty of Engineering and Architecture, 32(4), pp. 135-146, December 2017

\title{
Nötrosofik Üyelik Fonksiyonlu Bulanık Mantık-PID (NBMD-PID) ve Geleneksel Bulanık Mantık-PID (BMD-PID) Denetleyicinin Gerçek Zamanlı Karşılaştırılması
}

\author{
Mehmet Serhat CAN"1, Ömerül Faruk ÖZGÜVEN² \\ ${ }^{1}$ Gaziosmanpaşa Üniversitesi, Zile Meslek Yüksekokulu, Mekatronik Bölümü, Tokat \\ ${ }^{2}$ İnönü Üniversitesi, Biyomedikal Mühendisliği Bölümü, Malatya
}

Öz

Geliş tarihi: 06.02.2017 Kabul tarihi: 19.12 .2017

$\mathrm{Bu}$ çalışmada, giriş değişkenlerinin nötrosofik küme teorisindeki doğru $(T)$, belirsiz $(I)$ ve yanlış $(F)$ üyelik fonksiyonları kullanılarak, evrensel küme üzerindeki dağılımlarının gruplandırıldığı nötrosofik üyelik değerli bulanık mantık-PID (NBMD-PID) denetleyici ile geleneksel bulanık mantık-PID denetleyicinin (BMD-PID) gerçek zamanlı karşılaştırılması yapılmıştır. Matlab/Simulink yazılımında NBMD-PID denetleyici ve geleneksel BMD-PID denetleyici tasarlanmıştır. NBMD-PID ve BMD-PID denetleyici kontrol bloklarından alınan kontrol sinyali ile sabit mıknatıslı doğru akım (PMDC) motorunun devir hızı gerçek zamanlı olarak kontrol edilmiştir. PMDC motor devir hızı, motor miline bağlı artımsal devir sensöründen alınan devir bilgileri PCI-1711 veri toplama (DAQ) kartı üzerinden bilgisayar (PC) ortamına aktarılarak ölçülmüştür. NBMD-PID ve BMD-PID denetleyici kontrol çıkış işaretine göre PCI-1711 veri toplama (DAQ) kartından alınan analog çıkış işareti, mikrodenetleyici ile PWM işaretine dönüştürülmüştür. PWM işareti motor sürücü devresine uygulanarak motor devir hızının, girişten istenen devir hızını takip etmesi sağlanmıştır. Buna göre her iki kontrolörden, girişten istenen hıza göre çıkış cevapları alınmış ve grafik sonuçları karşılaştırılmıştır. NBMD-PID kontrolöründen elde edilen sonuçların, klasik BMD-PID kontrolörden elde edilen sonuçlara göre, daha hızlı, daha az aşımlı ve daha kararlı olduğu görülmüştür.

Anahtar Kelimeler: Bulanık mantık denetleyici, Nötrosofi, PMDC motor, Gerçek zamanlı kontrol

\section{Real-Time Comparison of Fuzzy Logic-PID Controller Having Neutrosophic Membership Function (NFLC-PID) and Traditional Fuzzy Logic-PID (FLC-PID) Controller}

\begin{abstract}
In this study, the neutrosophic membership-valued fuzzy logic-PID (NFLC-PID) controller, in which distributions of its input variables grouped on the universal set by using the true (T), indeterminacy (I) and false (F) membership functions, has been compared in real-time with the conventional fuzzy logicPID controller (FLC-PID). In Matlab/Simulink software, NFLC-PID controller and conventional FLCPID controller are designed. Speed of the permanent magnet direct current (PMDC) motor is controlled by control signal obtaiined from the NFLC-PID and FLC-PID controller control blocks, in real time. The
\end{abstract}

*Sorumlu yazar (Corresponding author): Mehmet Serhat CAN, mehmetserhat.can@gop.edu.tr 
PMDC motor speed is measured by transferring the speed pulses from the incremental speed sensor connected to the motor shaft to the computer (PC) using a PCI-1711 data acquisition (DAQ) card. Based on the NFLC-PID and the FLC-PID controller control output signal, the analog output signal from the PCI-1711 data acquisition (DAQ) card is converted to a PWM signal by the microcontroller. The PWM signal is applied to the motor drive circuit to ensure that the motor speed is followed by the desired speed. Consequently, the output responses are taken from the two controllers and plotted along with the desired speed input, then the graphical results are compared. The results obtained with the NFLC-PID controller are found to be faster, with less overshoot and more stable than the results obtained with the conventional FLC-PID controller.

Keywords: Fuzzy logic controller, Neutrosophy, PMDC motor, Real-time control

\section{GİRIŞ}

Klasik küme veya mantık teorisinde, bir elemanın bir kümeye aitliği 0 ve 1 sayıları kullanılmak suretiyle, keskin bir biçimde derecelendirilir. Yani eleman o kümeye ya dâhildir (1 durumu) ya da dâhil değildir (0 durumu). Açıktır ki, günlük yaşantımızda, bir olguya değer vermede ara geçiş değerlerini yani bulanık/gri değerleri de kullanırız. Örneğin havanın sıcaklığını değerlendirirken, "sıcak, biraz sıcak, 1lık, biraz soğuk ve soğuk" gibi derecelendirmeler yaparız. $\mathrm{Bu}$ sebeple, klasik küme teorisi ara durum değerlerini ifade edememektedir. Klasik küme teorisindeki bu yetersiz durum, Bulanık Mantık (BM) teorisi ile çözülmek istenmiştir [1]. BM'da klasik mantığın çözüm getiremediği ara geçiş değerlerini (bulanık/gri) de hesaba alması yönüyle, klasik mantığa göre çok daha zengin bir durum değerlendirmesi sağlanmaktadır. Ayrıca bulanık/gri değerlerin hesaba katılıyor olması, bulanık mantığı insansı düşünme mantığına yaklaştırmaktadır.

Smarandache, bulanık mantığın genişletilmiş ve özel bir biçimi olarak nötrosofi ve nötrosofik küme teorisini ortaya atmıştır [2]. Nötrosofide bir eleman, doğru (Truth $=T$ ), belirsiz (Indeterminacy $=I)$ ve yanlış (Falsity $=F$ ) şeklinde üç üyelik değeri kullanılarak temsil edilir. Nötrosofik küme teorisinde, bir $E$ evrensel kümesindeki $A$ alt kümesi içindeki $x$ elemanının üyelik değeri $x(0.3$, $0.8,0.5)$ şeklinde gösterilir. Bu gösterim $x(T, I, F)$ gösterimine denk gelir. Bu gösterimde $x$ elemanı 0.3 değeri ile $A$ kümesine dâhil, 0.8 değeri ile belirsiz ve 0.5 değeri oranınca da dâhil değildir. $T+I+F \quad$ toplamının 1 olma zorunluluğu bulunmamaktadır [3]. T, I ve $F$ değerleri gerçel değerli olmak şartıyla, sürekli, ayrık, tek değerli, sonlu (sayılabilen veya sayılamayan), sonsuz veya farklı alt küme kesişimleri veya birleşimleri şeklinde de olabilir [3]. Açık bir şekilde görüldüğü gibi, bulanık küme teorisinden farklı olarak, bir eleman, nötrosofik küme teorisinde belirsizlik değerine ve yanlışlık değerine sahiptir.

PID denetleyiciler, otomatik kontrol disiplininde, özellikle endüstriyel uygulamalarda kolay tasarım ve dayanıklılık gibi avantajları sağladığından yoğun bir kullanıma sahiptir [4,5]. PID denetleyicide kontrol edilen sistemden alınan hata $K_{p}$ (oransal), toplam sistem hatası $K_{i}$ (integral) ve hatanın birim zamandaki değişimi $K_{d}$ (türevsel) katsayıları ile çarpılır ve bu çarpımlar toplanır. Böylece PID denetleyicinin kontrol sinyali elde edilir. $K_{p}, K_{i}$ ve $K_{d}$ katsayıları sirasıyla oransal, integral ve türevsel katsayılar olarak isimlendirilir.

\section{2. ÖNCEKİ ÇALIŞMALAR}

PID denetleyici, sahip olduğu avantajlarla birlikte, kararsız ve salınımlı sistemlerde istenilen kontrol performanslarını sağlayamamaktadır [6]. Bu tür sistem kontrolleri için, PID denetleyiciye alternatif olarak BMD kullanılabilir. İlk BMD Mamdami tarafından sunulmuştur [7]. Araştırmacılar, PID denetleyici ve BMD bir araya getirilerek karma BMD-PID denetleyiciler önermişlerdir [8-11].

BM denetleyici tasarım aşamasında, kontrol edilmek istenen sisteme ait giriş değişkenlerinin BM operatörleri kullanılarak işlenebilmesi için, anlık gerçek (kesin) değerlerinin bulanık değerlere dönüştürülmesi gerekir ki bu aşama 
"bulanıklaştırma" (fuzzification) olarak adlandırılır. $\mathrm{Bu}$ aşamada kesin giriş değerleri, uygulama tipi ve uzman kişinin tecrübesine dayalı belirlenmiş bir takım üyelik fonksiyonlarından geçirilir. Seçilecek üyelik fonksiyonlarının tipleri, sayıları ve bu üyelik fonksiyonlarının evrensel küme üzerindeki dağılımları, kontrol sonuçları üzerinde etkili olmaktadır [12,13].

BMD tasarımında bulanıklaştırma aşaması için, nötrosofik üyelik fonksiyonlarının kullanımı ile ilgili bir çalışma sunulmuştur [14]. Bu çalışmada, bir PMDC motorun dönüş açısının kontrolü için NBMD-PID denetleyici önerilmiş, MATLAB/SIMULINK ortamında bir benzetim çalışmasında bulunulmuştur. Can ve arkadaşlarının çalışmalarında, hata ve hatanın değişimi için iki ayrı BMD birimi kullanmışlardır. Her bir BMD birimindeki bulanıklaştırma aşamasında, giriş değişkenleri için evrensel küme $T, I$ ve $F$ bölgelerine ayrıştırılmış ve bu bölgeler nötrosofik üyelik fonksiyonları olarak nitelendirilmiştir.

Can ve arkadaşlarının benzetim çalışmaları, kontrol sonuçlarını iyileştirdiği yönündedir. Ancak gerçek bir sistem üzerinde sonuçların elde edilmesi çalışma bulgularının teyidi açısından önemlidir. $\mathrm{Bu}$ çalışmada, Can ve arkadaşlarının benzetim çalışmasının bir adım ötesi olarak, PMDC motorun devri sayısı kontrolü PCI-1711 veri toplama kartı kullanılarak gerçek zamanlı olarak gerçekleştirilmiştir. Bu çalışmada da, hata ve hata değişiminin her birisi için ayrı ayrı BMD birimi ve bulanıklaştırma aşamasında $T, I$ ve $F$ üyelik fonksiyonları kullanılmıştır. BMD'de kullanılan üyelik fonksiyonları, evrensel küme üzerinde $T, I$ ve $F$ üyelik fonksiyonlarına göre belirli bölgelerde gruplandırılmıştır. Kural tablosunda ise bu üç üyelik fonksiyonlarının yerleşimlerine göre belirlenen üyelik fonksiyonlarından çıkış kuralları oluşturulmuştur. Çalışmada, NBMD-PID ve BMD-PID denetleyicilerin gerçek zamanlı sonuçları kıyaslanmıştır. Test sonuçlarına göre, NBMD-PID ile elde edilen sonuçlar, klasik BMD-PID ile elde edilen sonuçlara göre daha hızlı, daha az aşımlı ve daha kararlı olduğu tespit edilmiştir.

\section{MATERYAL VE METOT}

\subsection{Materyal}

\subsubsection{Nötrosofik Mantık ve Nötrosofik Küme}

Nötrosofik küme ve nötrosofik operatörler, BM'daki operatörler ile benzerlik göstermektedir. Nötrosofik yaklaşımda ilave olarak belirsizlik üyelik değeri de hesaba katılır. Bu bölümde, nötrosofik mantık ve nötrosofik küme teorisi ile ilgili bazı temel bilgiler sunulmuştur.

Tanım 1 [15] $X$ bir evrensel küme olsun. $x$ bu evrensel kümede bir eleman olsun. $X$ söylem evreninde bir $A$ nötrosofik alt kümesi olsun. $A$ alt kümesi için;

$T_{A}(x)$ : Doğruluk üyelik fonksiyonu. $I_{A}(x)$ : Belirsizlik üyelik fonksiyonu. $F_{A}(x)$ : Yanlışlık üyelik fonksiyonu. $T_{A}(x), I_{A}(x)$ ve $F_{A}(x)$ fonksiyonları $] 0-, 1+[$ 'nın gerçel, standart ya da standart olmayan alt kümesidir.

$\left.T_{A}(x): X \rightarrow\right] 0^{-}, 1^{+}[$

$\left.I_{A}(x): X \rightarrow\right] 0^{-}, 1^{+}[$

$\left.F_{A}(x): X \rightarrow\right] 0^{-}, 1^{+}[$

$T_{A}(x), I_{A}(x)$ ve $F_{A}(x)$ fonksiyonlarının toplamı için bir sinırlama yoktur ve $0^{-} \leq \sup T_{A}(x)+\sup I_{A}(x)+$ sup $F_{A}(x) \leq 3^{+}$durumu geçerlidir.

Tanım 2 [15] A kümesi, $X$ içinde bir tek değerli nötrosofik küme (Single Valued Neutrosophic Set=SVNS).

$A=\left\{\left\langle x, T_{A}(x), I_{A}(x), F_{A}(x)\right\rangle: x \in X\right\}$.

$T_{A}(x): X \rightarrow[0,1]$

$I_{A}(x): X \rightarrow[0,1]$

$F_{A}(x): X \rightarrow[0,1]$

$0 \leq T_{A}(x)+I_{A}(x)+F_{A}(x) \leq 3$ her $x \in X$ için geçerlidir.

Tanım 3 [15] $A$ bir SVNS olsun. A'nın komplementi $A_{c}$ ile gösterilir ve her $x \in X$ için; 
$T_{A c}(\mathrm{x})=F_{A}(x)$

$I_{A c}(\mathrm{x})=1-I_{A}(x)$

$F_{A c}(\mathrm{x})=T_{A}(x)$

$A_{c}=\left\{\left\langle x, F_{A}(x), 1-I_{A}(x), T_{A}(x)\right\rangle: x \in X\right\}$ için geçerlidir.

Tanım 4 [15] SVNS $A$ ve SVNS $B$ kümeleri için, $A \subseteq B$ ve $B \subseteq A$ koşulunun sağlanması durumunda $A=B$ 'dir.

Tanım 5 [16] $A, B$ ve $C$ nötrosofik kümeler ve her $x \in X$ dir. $T_{A}(x), I_{A}(x), F_{A}(x), T_{B}(x), I_{B}(x), F_{B}(x)$ ifadeleri, sırasıyla, doğruluk üyelik fonksiyonu, belirsizlik üyelik fonksiyonu ve yanlışlık üyelik fonksiyonudur.

Kesişim/VE operatörü:

$T_{C}(x)=\min \left(T_{A}(x), T_{B}(x)\right)$

$I_{C}(x)=\min \left(I_{A}(x), I_{B}(x)\right)$

$F_{C}(x)=\max \left(F_{A}(x), F_{B}(x)\right)$

Birleşim/VEYA operatörü:

$T_{C}(x)=\max \left(T_{A}(x), T_{B}(x)\right)$

$I_{C}(x)=\max \left(I_{A}(x), I_{B}(x)\right)$

$F_{C}(x)=\min \left(F_{A}(x), F_{B}(x)\right)$

\subsubsection{PID Denetleyici, NBMD ve BMD Denetleyiciler}

PID kontrolde anlık hata değeri $K_{p}$, toplam hata $K_{i}$ ve hatanın birim zamandaki değişimi $K_{d}$ adı verilen üç katsayı ile çarpılır ve bu çarpımlar toplanmak suretiyle kontrol işareti elde edilir. $K_{p}$, $K_{i}$ ve $K_{d}$ katsayılarının, sistemden elde edilmek istenen en uygun sistem cevabının alınması için ayarlanması gerekir. Bir PID denetleyicinin zaman domenindeki kontrol işaretinin gösterimi aşağıdaki denklemlerde verilmiştir.

$$
\begin{aligned}
& e(t)=r(t)-y(t) \\
& u(t)=K_{p} e(t)+K_{i} \int e(t) d t+K_{d} \frac{d}{d t} e(t)
\end{aligned}
$$

Denklem 1 ve Denklem 2'de $r(t)$ referans değerini, $e(t)$ hata değerini, $u(t)$ kontrol işaretini ve $y(t)$ çıkış işaretini göstermektedir.
PID denetleyici tasarımında, kontrol edilecek sistemin karakteristiğine bağlı olarak, $K_{p}, K_{i}$ ve $K_{d}$ çarpanlarından birisi ya da ikisi sıfır değerini alabilir ve bu durumlarda P, PI, PD veya I denetleyici yapıları oluşur.

BMD'ler, PID denetleyicilere alternatif olarak doğrusalsızlık (nonlinearity) ve belirsizlik (uncertainty/indeterminacy) içeren sistemler için iyi sonuçlar üretebilmektedir [17-19]. BMD dört ana birimden oluşur. Bunlar, bulanıklaştırma birimi, veri tabanı, karar verme mantığı ve durulaştırma (netleştirme) birimidir. Genel olarak BMD'de giriş değişkenleri olarak hata ve hatanın değişimi kullanılır. Genel bir BMD blok diyagramı Şekil 1'de gösterilmiştir.

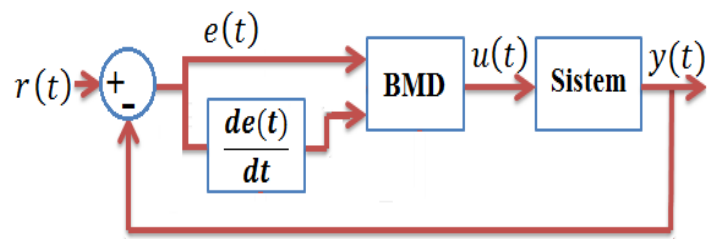

Şekil 1. Klasik BMD blok diyagramı

Bulanıklaştırmada, kesin giriş değişkenleri üyelik fonksiyonlarından geçirilir ve böylece giriş değişkenlerinin hangi bulanık alt kümeye ait olduğu elde edilmiş olur. Bulanıklaştırma için çoğunlukla üçgen, Gauss eğrisi, çan eğrisi, yamuk, Cauchy üyelik fonksiyonları kullanılır. Bulanıklaştırma aşamasını veri (kural) tabanı izler. Giriş değişkenlerinin sahip olduğu bulanık değerler, uzman kişinin tecrübesine bağlı olarak yazılan kural tabanında değerlendirilir ve bulanık operatörler kullanılarak bulanık kararlar oluşturulur. Durulaştırma (defuzification) biriminde, bulanık kurallar, sisteme uygulanabilir kesin kontrol sinyaline dönüştürülür.

Can ve arkadaşlarının önerdikleri NBMD-PID denetleyicide, bulanıklaştırma aşaması için, nötrosofik üyelik fonksiyonlarının kullanımını ve hata ve hatanın değişiminin iki ayrı BMD biriminde işlenmektedir. Şekil 2 araştırmacıların bu çalışmalarını göstermektedir. 


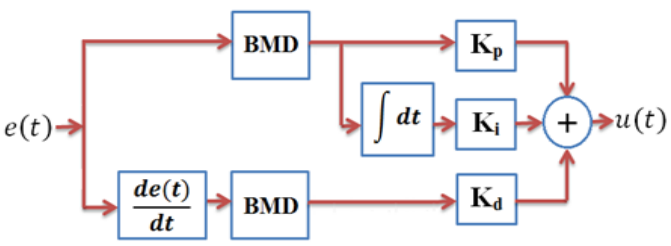

a)

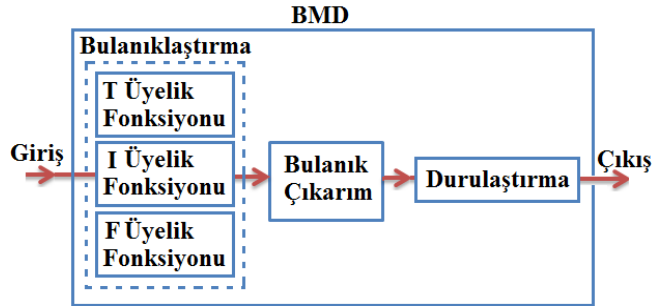

b)

Şekil 2. a) NBMD-PID denetleyici blok şeması, b) BMD’nin iç yapısı [14]

Şekil 2.b'den görülebileceği gibi, BMD birimlerinin giriş değişkenlerinin bulanıklaştırılması aşamasında $T, I, \quad F$ üyelik fonksiyonları kullanılmıştır. Burada evrensel küme aralığı $T, \quad I, \quad F$ üyelik fonksiyonları ile gruplandırılmıştır. Evrensel kümenin üzerinde büyük hata değerlerine doğru yaklaşıldıkça $F$ üyelik değeri artmakta, sıfır değerine yaklaşıldıkça $F$ üyelik değeri azalmakta ve $T$ üyelik değeri ise artmaktadır. $T, I$ ve $F$ üyelik değerlerinin artmasına bağlı olarak kurallarda kullanılan üyelik fonksiyonlarının dağılım yoğunluğu da artıp azalmaktadır. Evrensel kümenin orta bölgesinde ise $I$ üyelik değeri en büyük değeri almaktadır. (Şekil 5)

\subsection{Metot}

Çalışmada, NBMD-PID denetleyici ve BMD-PID denetleyici ile PMDC motorun devir sayıs kontrolü PCI-1711 veri toplama kartı kullanılarak gerçek zamanlı olarak gerçekleştirilmiş ve denetleyici performansları kıyaslanmıştır. Hem NBMD-PID denetleyicide hem de BMD-PID denetleyicinin performans kıyaslamasının doğru yapılabilmesi için, BM birimlerinin giriş değişkenlerinin evrensel küme aralıkları eşit seçilmiştir. Deney çalışmalarında, NBMD-PID denetleyici için Şekil 2'de, BMD-PID denetleyici için Şekil 3'te verilen yapı kullanılmıştır.

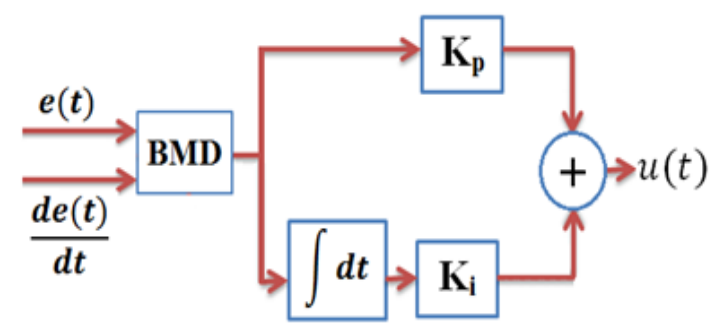

Şekil 3. BMD-PID denetleyici blok şeması

Şekil 3 'te görüldüğü gibi, BMD-PID denetleyicide $K_{p}$ ve $K_{i}$ çarpanları kullanılmış, ancak ayrıca $K_{d}$ çarpanı kullanılmamıştır. Bunun sebebi, hata değişiminin zaten BMD biriminde işleniyor olmasındandır. BMD-PID denetleyicide kullanılan üyelik fonksiyonları Şekil 4'te, NBMD-PID denetleyicide kullanılan üyelik fonksiyonları Şekil 5'te verilmiştir. Hata ve hatanın değişimi için Şekil 5'deki aynı üyelik fonksiyonları kullanılmıştır.

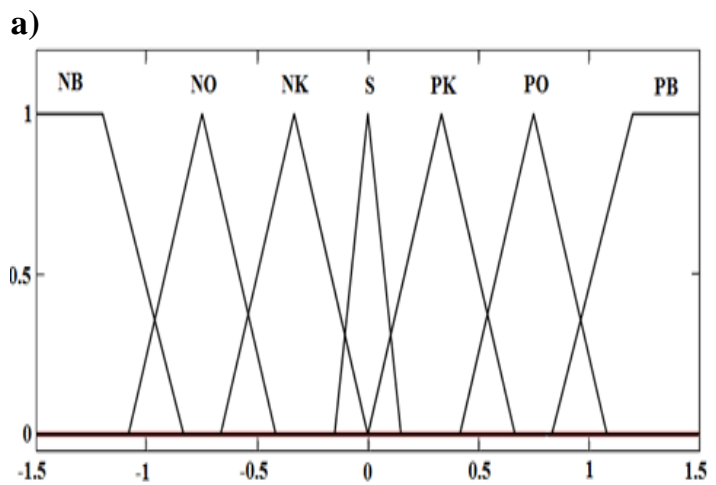

b)

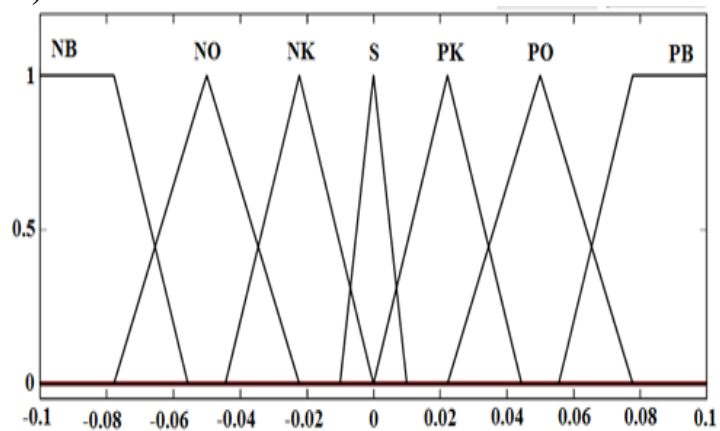

Şekil 4. BMD-PID denetleyiciye ait üyelik fonksiyonları. a) Hata, b) Hatanın değişimi [14] 

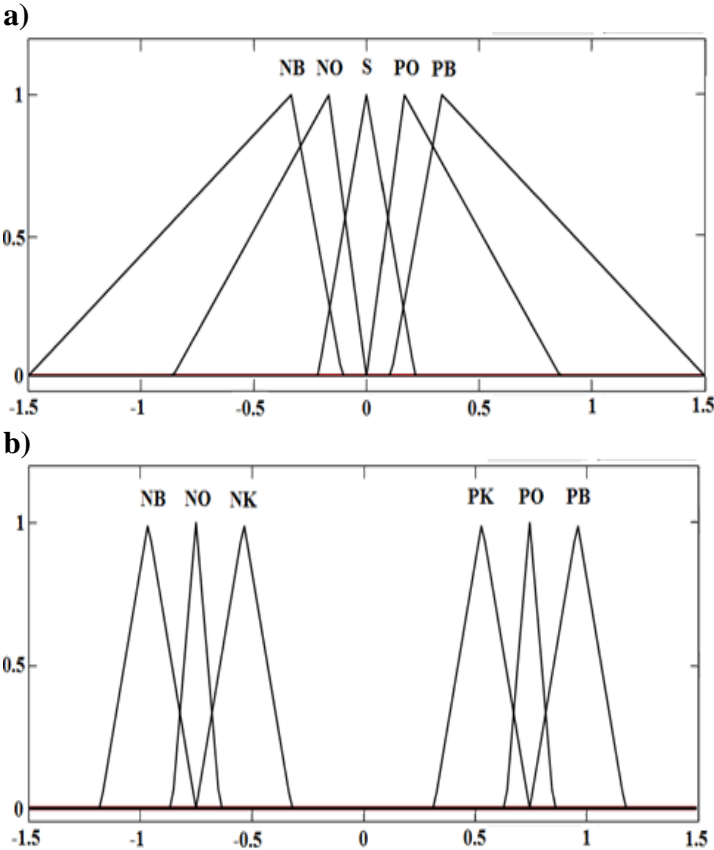

c)

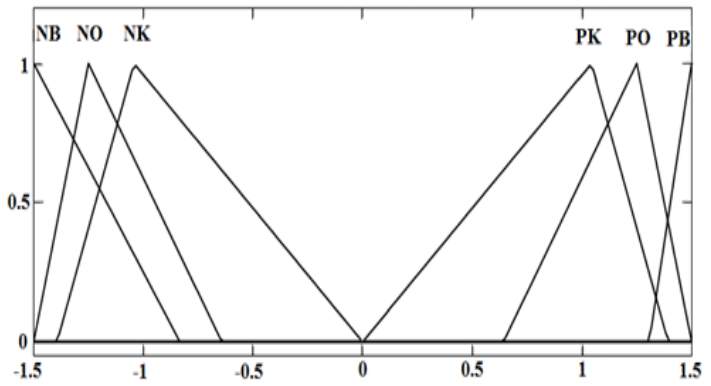

Şekil 5. NBMD-PID denetleyicideki $T, I$ ve $F$ üyelik değerlerinin evrensel küme üzerinde gruplandırılması a) $T$ üyelik fonksiyonları b) $I$ üyelik fonksiyonları c) $F$ üyelik fonksiyonları [14]

Şekil 4'teki ve Şekil 5'deki giriş üyelik fonksiyonlarında kullanılan NB, NO, NK, S, PK, PO ve PB kısaltmaları sırasıyla, "Negatif Büyük", "Negatif Orta", "Negatif Küçük", "Sıfır”, "Pozitif Küçük”, "Pozitif Orta", "Pozitif Büyük" dilsel ifadelerini göstermektedir.

Şekil 2 ve Şekil 3'te kullanılan BMD birimlerinin her birinde aynı çıkış üyelik fonksiyonları kullanılmıştır. BMD'lerdeki çıkış üyelik fonksiyonları aşağıdaki Şekil 6'da verilmiştir.

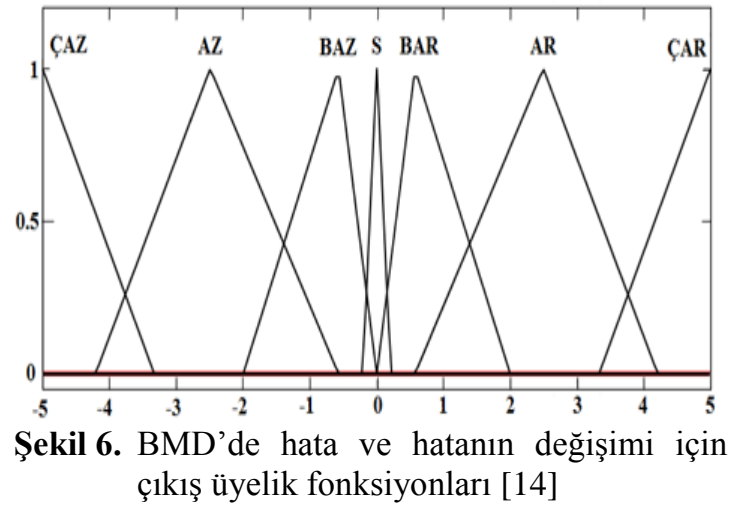

BMD-PID denetleyicide kullanılan kural tablosu Çizelge 1'de ve NBMD'de kullanılan kural tablosu Çizelge 2'de verilmiştir. Çizelge 1, Çizelge 2 ve Şekil 6'da kullanılan ÇAZ, AZ, BAZ, S, BAR, AR, ÇAR terimleri sırasıyla "Çok Azalt", "Azalt", "Biraz Azalt", "Sifır", "Biraz Artır", "Artır" ve "Çok Artır" dilsel ifadelerini temsil etmektedir. Çizelge 2'deki kurallarda kullanılan e_T, e_I ve e_F sırasıyla doğruluk, belirsizlik ve yanlışlık üyelik değerlerini göstermektedir.

Çizelge 1'de, BMD biriminde kullanılan kurallar, literatürde alışılagelmiş gösterim şekli ile verilmiştir. NBMD’nin kuralları, alışılagelmiş biçimde gösterilemediği için, Çizelge 2'deki gibi liste halinde verilmiştir. Çizelgelerde " $e$ " hatayı, " $c e$ " hatanın değişimini temsil etmektedir.

Çizelge 1. BMD-PID denetleyicide kullanılan kurallar

\begin{tabular}{|c|c|c|c|c|c|c|c|c|}
\hline & & \multicolumn{7}{|c|}{$c e$} \\
\hline \multirow{8}{*}{$e$} & & NB & NO & NK & $\mathrm{S}$ & PK & $\mathrm{PO}$ & PB \\
\hline & NB & ÇAZ & ÇAZ & ÇAZ & $\mathrm{AZ}$ & BAZ & BAZ & $S$ \\
\hline & NO & ÇAZ & AZ & AZ & $\mathrm{AZ}$ & BAZ & S & BAR \\
\hline & NK & ÇAZ & $\mathrm{AZ}$ & BAZ & BAZ & $\mathrm{S}$ & BAR & AR \\
\hline & S & ÇAZ & $\mathrm{AZ}$ & BAZ & S & BAR & AR & ÇAR \\
\hline & PK & $\mathrm{AZ}$ & BAZ & $S$ & BAR & BAR & AR & ÇAR \\
\hline & PO & BAZ & S & BAR & AR & $\mathrm{AR}$ & AR & ÇAR \\
\hline & PB & $\mathrm{S}$ & BAR & BAR & $\mathrm{AR}$ & CAR & CAR & CAR \\
\hline
\end{tabular}


Çizelge 2. NBM-PID denetleyicide kullanılan kuralların listesi [14]

\begin{tabular}{|c|}
\hline 1. If ( $\mathrm{e}_{-} \mathrm{T}$ is $\mathrm{S}$ ) or (e_F is $\mathrm{PK}$ ) then (output1 is $\mathrm{S}$ ) \\
\hline 2. If (e_T is $\mathrm{S}$ ) or (e_F is NK) then (output1 is $\mathrm{S}$ ) \\
\hline 3. If ( $\mathrm{e} \_\mathrm{T}$ is $\left.\mathrm{PO}\right)$ or $\left(\mathrm{e} \_\mathrm{F}\right.$ is $\left.\mathrm{PK}\right)$ then (output1 is $\mathrm{BAR}$ ) \\
\hline 4. If (e_T is NO) or (e_F is NK) then (output1 is BAZ) \\
\hline 5. If ( $\mathrm{e}_{-} \mathrm{T}$ is $\left.\mathrm{PO}\right)$ or ( $\mathrm{e}_{-} \mathrm{I}$ is $\left.\mathrm{PK}\right)$ or $(\mathrm{e}-\mathrm{F}$ is $\mathrm{PK})$ then (output 1 is $\left.\mathrm{BAR}\right)$ \\
\hline $\begin{array}{l}\text { 6. If (e_T is NO) or (e_I is NK) or (e_F is NK) then (output1 is } \\
\text { BAZ) }\end{array}$ \\
\hline 7. If $\left(\mathrm{e}_{-} \mathrm{T}\right.$ is $\left.\mathrm{PB}\right)$ or $\left(\mathrm{e}_{-} \mathrm{I}\right.$ is $\left.\mathrm{PK}\right)$ or $\left(\mathrm{e} \_\mathrm{F}\right.$ is $\left.\mathrm{PK}\right)$ then (output1 is $\left.\mathrm{BAR}\right)$ \\
\hline 8. If (e_T is NB) or (e_I is NK) or (e_F is NK) then (output1 is BAZ) \\
\hline 9. If (e_T is $\mathrm{PB}$ ) or ( $\mathrm{e} \_\mathrm{I}$ is $\left.\mathrm{PO}\right)$ or $\left(\mathrm{e} \_\mathrm{F}\right.$ is $\mathrm{PK}$ ) then (output1 is ART) \\
\hline 10. If (e_T is NB) or (e_I is NO) or (e_f is NK) then (outputl is AZ) \\
\hline 11. If (e_T is $\mathrm{PB}$ ) or (e_I is PB) or (e_F is PO) then (output1 is ART) \\
\hline 12. If ( $\left(e_{-} T\right.$ is $\left.N B\right)$ or $\left(e_{-} I\right.$ is $\left.N B\right)$ or $\left(e_{-} F\right.$ is $\left.N O\right)$ then (output1 is $\left.A Z\right)$ \\
\hline 13. If ( $e_{-} T$ is $\left.P B\right)$ or $\left(e_{-} I\right.$ is $\left.P B\right)$ or ( $e_{-} F$ is $\left.P O\right)$ then (output 1 is $\left.A R\right)$ \\
\hline 14. If $\left(\mathrm{e}_{-} \mathrm{T}\right.$ is $\left.\mathrm{NB}\right)$ or $\left(\mathrm{e}_{-} \mathrm{I}\right.$ is $\left.\mathrm{NB}\right)$ or $\left(\mathrm{e}_{-} \mathrm{F}\right.$ is $\left.\mathrm{NO}\right)$ then (output1 is $\left.\mathrm{AZ}\right)$ \\
\hline 15. If (e_T is $\mathrm{PB})$ or (e_F is $\mathrm{PO})$ then (output1 is ÇAR) \\
\hline 16. If (e $\mathrm{T}$ is $\mathrm{NB}$ ) or (e F is NO) then (output1 is C $\mathrm{AZ}$ ) \\
\hline 17. If (e_T is $\mathrm{PB}$ ) or (e F is $\mathrm{PB}$ ) then (output 1 is $\mathrm{CAR}$ ) \\
\hline 18. If (e $\mathrm{T}$ is $\mathrm{NB}$ ) or (e F is NB) then (output1 is C CAZ) \\
\hline 19. If (e_F is PB) then (output1 is ÇAR) \\
\hline 20. If (e $F$ is NB) the \\
\hline
\end{tabular}

Çizelge 2'de verilen kurallar, NBMD-PID'de hem hata ve hem de hatanın değişimi için kullanılmıştır. Uygulamada kullanılan test düzeneği aşağıdaki Şekil 7'de verilmiştir.

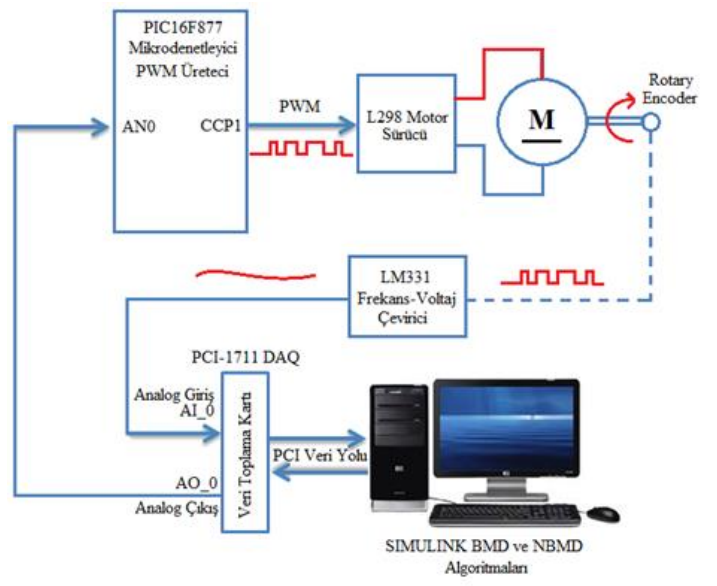

Şekil 7. Uygulamada kullanılan deney düzeneğine ait blok gösterim

Şekil 7'de, PMDC motorunun miline her bir tur için 200 pals üreten artımsal (incremental) rotary enkoder bağlanmıştır. Bu enkoder A ve B şeklinde iki pals çıkış kanalına sahiptir. Rotary enkoderin A kanalından alınan palsler, LM331 Frekans-Gerilim dönüştürücü entegre kullanılarak analog gerilime dönüştürülmüştür. Bu analog gerilimler PCI-1711
DAQ'nun sıfırıncı analog giriş kanalı (AI_0) ile gerçek zamanlı olarak PC ortamına alınmıştır. Alınan bu gerilim değeri, SIMULINK'te koşturulan algoritmalar için gerçek zamanlı PMDC motor hizı geri besleme sinyalidir. Kontrol algoritmalarınca üretilen kontrol sinyalleri, yine PCI-1711 DAQ'nun sıfırıncı analog çıkış kanalı (AO_0) ile PIC16F877 mikrodenetleyicinin AN0 sıfırıncı analog giriş ucuna uygulanmıştır. $\mathrm{Bu}$ düzenekte PIC mikrodenetleyici basitçe PWM üreteci olarak kullanılmıştır. PIC16F877 mikrodenetleyicinin kontrol sinyali üzerinde başka bir etkisi bulunmamaktadır. PIC16F877 mikrodenetleyici, analog değeri 0-5 V gerilim seviyesi arasında okuyup, bu gerilim seviyesine göre \%0-\%100 PWM çevrimine göre ( $D=$ Duty), CCP1 (birinci PWM çıkış1) ucuna ve oradan L298 motor sürücünün birinci Enable (yetkilendirme) ucuna göndermektedir, böylece PMDC motor devir hızı ayarlanmıştır.

\section{BULGULAR}

Bu kısımda, yukarıda sunulan metot çerçevesinde NBMD-PID ile klasik BMD-PID denetleyicilerin performansları, bir doğru akım motorunun devir hızı kontrolünde, PCI-1711 DAQ kullanılarak gerçek zamanlı olarak testler yapılarak kıyaslanmıştır. Testler farklı $K_{p}, \quad K_{i}$ ve $K_{d}$ değerlerine göre motor devrinin verilen referans değerini yakalama ve takip etme durumları bakımından gerçekleştirilmiştir. Ayrıca, hata değişiminin (ce) evrensel küme aralığının $[-0,1,+0,1]$ ve $[-0,2,+0,2]$ seçildiği iki test şeklinde düzenlenmiştir. $e$ aralığı ise tüm testlerde $[-1,5,+1,5]$ olarak alınmıştır. $\mathrm{Bu}$ sayede, hata değişimin aralığının seçiminin, NBMD-PID ve BMD-PID arasında nasıl bir farklılık ortaya çıkardığı tespit edilmeye çalışılmıştır. $[-0,1,+0,1]$ aralığı, $c e$ 'nin yaklaşık $\pm \% 6$ 'lık değişim aralığına ve $[-0,2,+0,2]$ aralığı ise $c e$ 'nin yaklaşık $\pm \% 12$ değişim aralığına karşılık gelmektedir.

Deney düzeneğinde kullanılan PMDC motorun gerilim-hız karakteristiğini elde etmek için, PCI-1711 DAQ'nun analog çıkışından 
PIC16F877'nin AN0 ucuna kontrolsüz voltaj seviyeleri (BMD-PID ve NBMD-PID kullanılmadan), uygulanmış ve aşağıdaki Şekil 8'de gösterilen eğri elde edilmiştir.

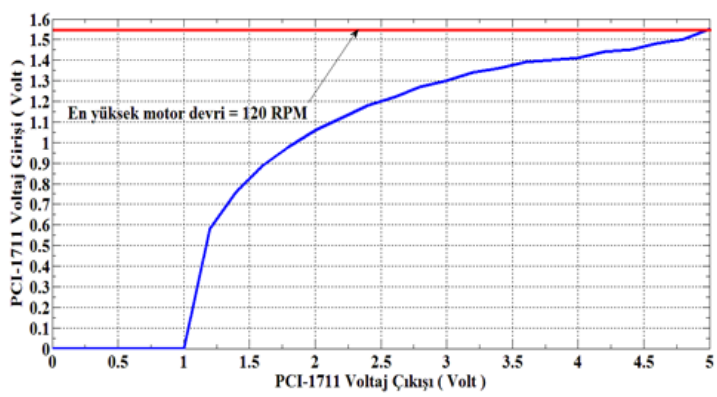

Şekil 8. Farklı gerilim değerlerine göre motorun devir sayısının değişimi grafiğ

Şekil 8'de gösterilen kırmızı renkli doğru, PCI-1711 DAQ'dan verilen en yüksek gerilim değeri olan $5 \mathrm{~V}$ karşılık, motor devrinin aldığı en yüksek değer olan $120 \mathrm{rpm}$ (devir/dk) değerini göstermektedir.

Önerilen yöntemin geleneksel BMD-PID ile karşılaştırması işlemi, $c e^{\prime}$ 'nin üyelik fonksiyonlarının evrensel küme aralığının farklı değerleri için test edilmiştir. Bu sayede önerilen yöntem ve geleneksel BMD-PID'nin ce üyelik fonksiyonlarının evrensel küme aralığının seçimine olan duyarlılıkları test edilmek istenmiştir. Aşağıdaki Şekil 9'da ce'nin evrensel küme aralığının $[-0,1,+0,1]$ olduğu aralık için farklı $K_{p}$, $K_{i}$ ve $K_{d}$ değerleri için NBMD-PID ve BMD-PID ile elde edilmiş sonuçlar verilmiştir.

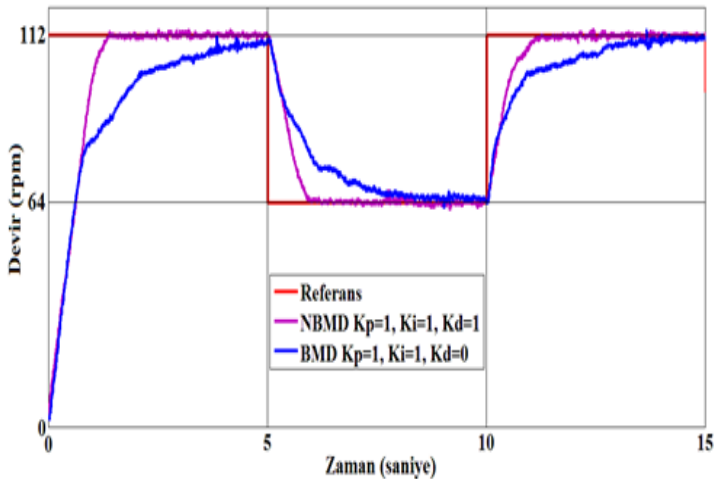

a)

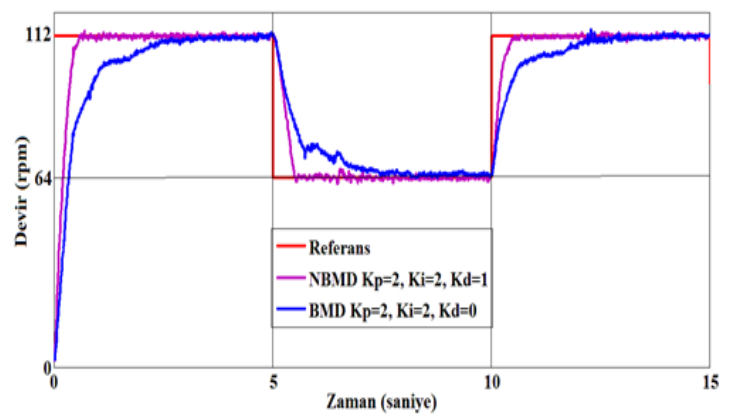

b)

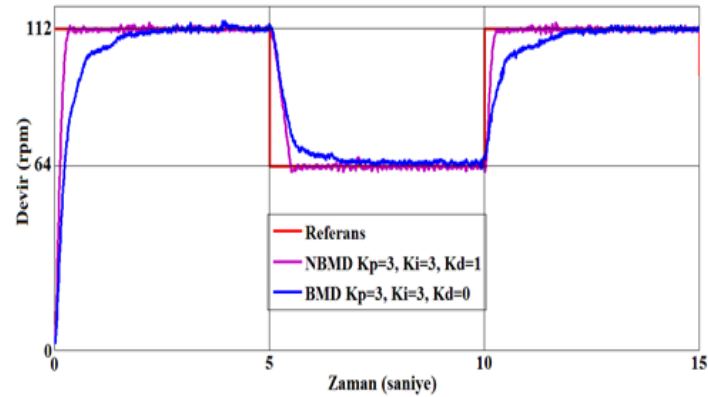

c)

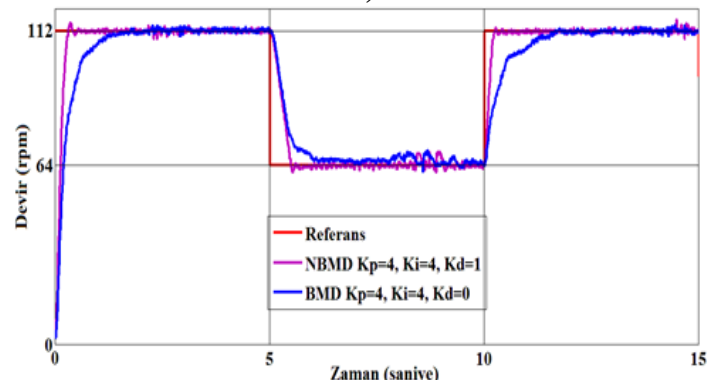

d)

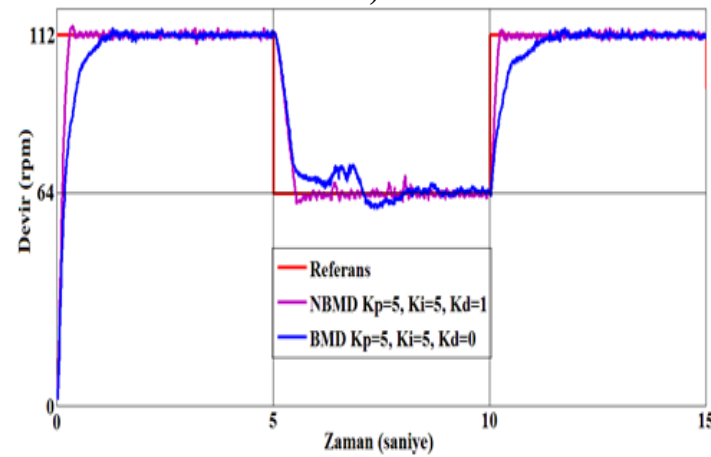

e)

Şekil 9. $c$ 'nin evrensel küme aralığının $[-0,1,+0,1]$ olduğu durumda farklı $K_{p}, K_{i}$ ve $K_{d}$ değerleri için NBMD-PID ve BMDPID performanslarının karşılaştırılması 
Şekil 10'da ce'nin evrensel küme aralığının $[-0,2,+0,2]$ olduğu aralık için farklı $K_{p}, K_{i}$ ve $K_{d}$ değerlerine göre elde edilmiş sonuçlar verilmiştir.

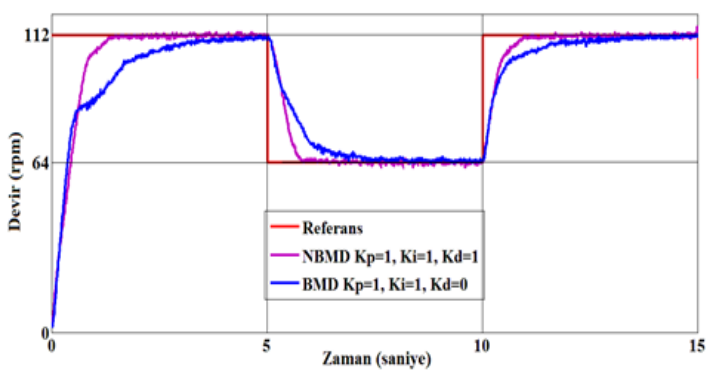

a)

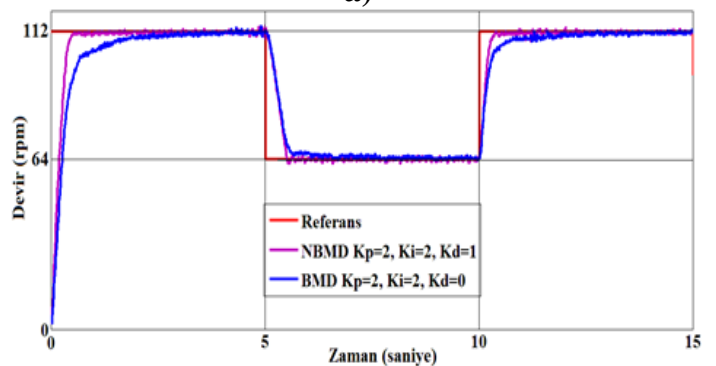

b)

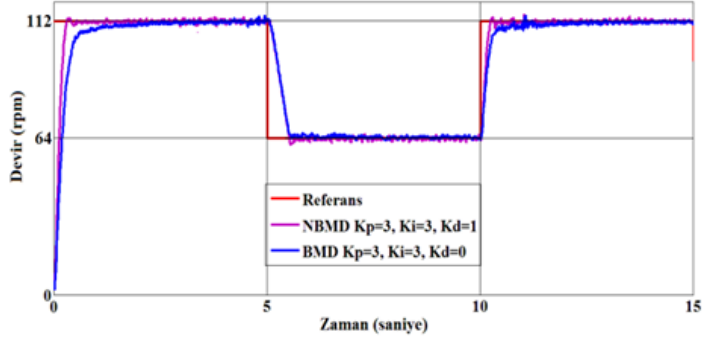

c)

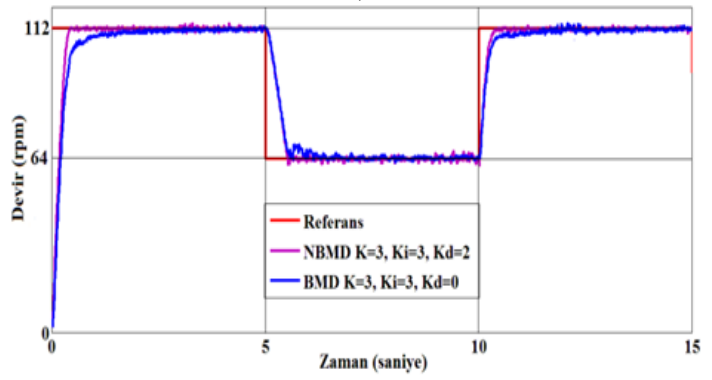

d)

Şekil 10. $c e$ 'nin evrensel küme aralığının $[-0,2,+0,2]$ olduğu durumda farklı $K_{p}, K_{i}$ ve $K_{d}$ değerleri için NBMD-PID ve BMD-PID performanslarının

karşılaştırılması
Şekil 9 ve Şekil 10'daki aynı $K_{p}, K_{i}$ ve $K_{d}$ değerleri için verilen grafikler incelendiğinde, geleneksel BMD, önerilen yönteme göre, $c e$ 'ye ait üyelik fonksiyonlarının evrensel küme aralığının seçimine daha çok duyarlı olduğu görülmektedir.

NBMD'nin türev bileşeninin ve çarpanının kontrol sonuçları üzerindeki etkisini göstermek üzere $K_{p}=3$ ve $K_{i}=3$ değerlerinde sabit tutulup, $K_{d}$ değeri birer birer artırılmıştır. Elde edilmiş sonuçlar aşağıdaki Şekil 11'deki gibidir.

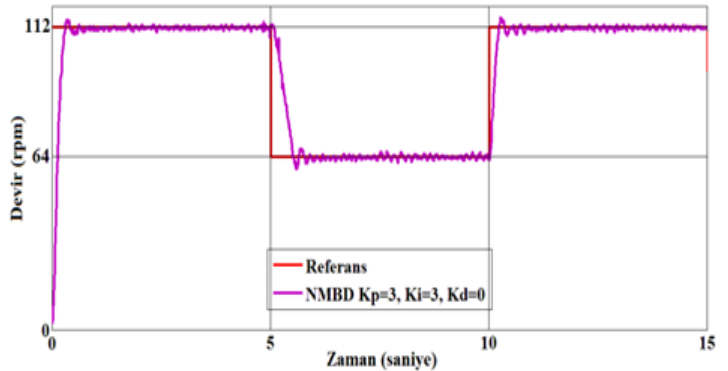

a)

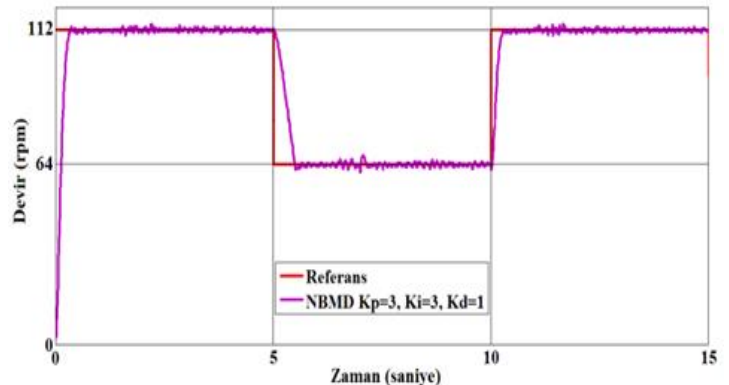

b)

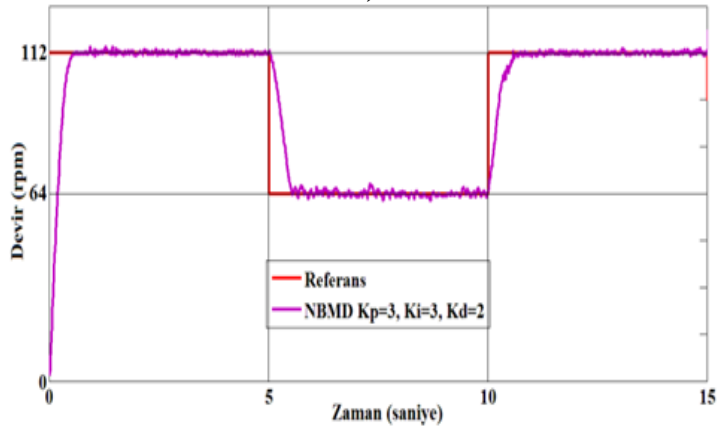

c)

Şekil 11. $c e^{\prime}$ nin evrensel küme aralığının $[-0,2,+0,2]$ olduğu durumda, $K_{p}=3, K_{i}=3$ ve farklı $K_{d}$ değerleri için NBMD-PID performanslarının karşılaştırılması 
Şekil 11'den görülebileceği gibi, $K_{d}$ değerinin artııılması aşım oranını azaltmış, yükselme ve oturma zamanlarını neredeyse değiştirmemiştir.

Takip eden kısımda, yukarıdaki testlerin benzerleri sinüzoidal bir referans işareti kullanılarak gerçekleştirilmiş̧ir. Referans işareti olarak ortalama genlik değeri $0,5 \mathrm{~V}$, tepe genlik değeri $1 \mathrm{~V}$, frekans1 $2 \mathrm{rad} / \mathrm{sn}$ olan bir sinüs işareti kullanılmıştır. $\mathrm{Bu}$ gerçek zamanlı deneysel çalışmada, yukarıdaki Şekil 11'de elde edilen sonuçlara göre, $K_{p}=3, K_{i}=3$ ve $K_{d}=2$ (NBMD-PID) ve $K_{d}=0$ (BMD-PID) değerleri seçilmiştir. Şekil 12 ve Şekil 13'te, ce'nin evrensel küme aralığı $[-0,1,+0,1]$ olarak seçilmiş, Şekil 14 ve Şekil 15 'de ise $c e$ 'nin evrensel küme aralığı $[-0,2,+0,2]$ olarak seçilmiştir.

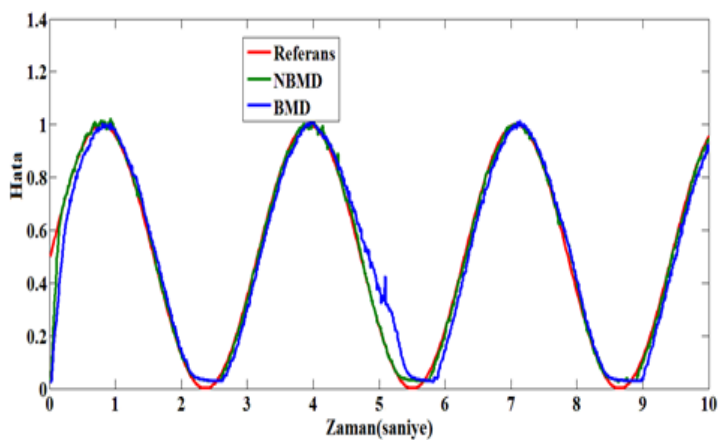

Şekil 12. $c e$ 'nin evrensel küme aralığ $[-0.1,+0.1]$ için sinüzoidal bir referans ve BMD-PID ile NBMD-PID referans işaretini izleme başarımları

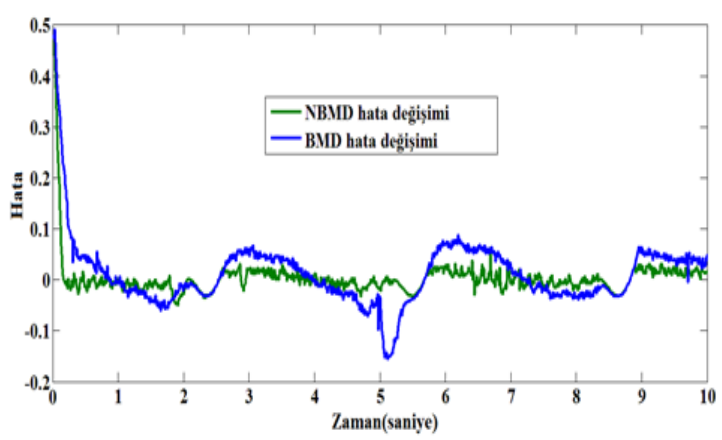

Şekil 13. BMD-PID ile NBMD-PID'lerin, $c e^{\text {'nin }}$ evrensel küme aralığı $[-0.1,+0.1]$ için sinüzoidal bir referans işaretini izlemedeki hata değişimleri

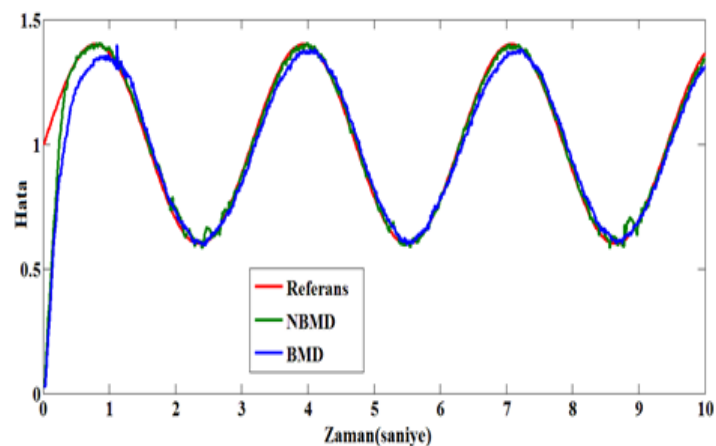

Şekil 14. $c e$ 'nin evrensel küme aralığ $[-0,2,+0,2]$ için sinüzoidal bir referans ve BMDPID ile NBMD-PID referans işaretini izleme başarımları

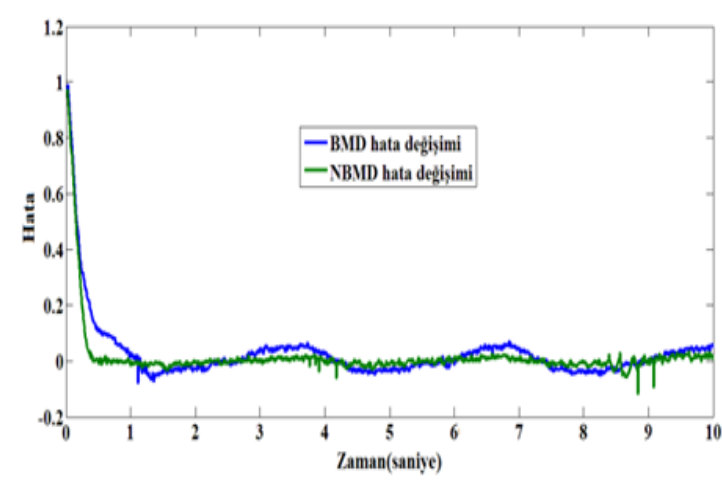

Sekil 15. BMD ile NBMD-PID'lerin, $c e$ 'nin evrensel küme aralığ $1[-0,2,+0,2]$ için sinüzoidal bir referans işaretini izlemedeki hata değişimleri

\section{SONUÇ VE ÖNERILER}

Çalışmada, üyelik fonksiyonlarının evrensel küme üzerinde nötrosofik küme yaklaşımı ile gruplandırılmasına dayalı NBMD-PID denetleyici ve geleneksel BMD-PID denetleyiciler, gerçek zamanlı olarak bir PMDC motor devir kontrolü üzerinde denenmiş ve bu iki denetleyicinin performansları kıyaslanmıştır. Testler, değişken basamak referans değerlerinde ve sinüzoidal referanslı yörünge takibi şeklinde gerçekleştirilmiştir. Uygulama sonuçlarına göre, NBMD-PID denetleyici ile daha kısa süreli yükselme zamanı ve daha az aşım oranları elde edilmiştir. Ayrıca, geleneksel BMD-PID 
denetleyicinin üyelik fonksiyonlarının evrensel küme aralıklarının seçimine daha duyarlı olduğu gözlemlenmiştir. $\mathrm{Bu}$ çalışmanın devamı olarak, kullanılan metotlar, PC ve DAQ kartı kullanılmadan bir mikrodenetleyici üzerinde gerçekleştirilecektir.

\section{KAYNAKLAR}

1. Zadeh, L. A., 1965. Fuzzy Sets, Information \& Control, 8, 338-353.

2. Smarandache, F., 2002. Neutrosophy a New Branch of Philosophy, Multi. Val. LogicSpecial Issue: Neutrosophy and Neutrosophic Logic, 8(3), 297-384 .

3. Smarandache, F., 2003. Definition of Neutrosophic Logic, a Generalization of the Intuitionistic Fuzzy Logic, Proceeding of the Third Conference of the European Society for Fuzzy Logic and Technology.

4. Shahrokhi, M., Zomorrodi, A., 2003. Comparison of PID Controller Tuning Methods, Proceedings of $8^{\text {th }}$ National Iranian Chemical Engineering Congress, Ferdowsi University, Mashhad, Iran.

5. Hussain, K.M., Zepherin, R.A.R., Kumar, M.S., Kumar, S.M. G., 2014. Comparison of PID Controller Tuning Methods with Genetic Algorithm for FOPTD System, Int. Journal of Engineering Research and Applications, 4(2), (Version 1), 308-314.

6. Mitsantisuk, C., Nandayapa, M., Ohishi, K., Katsura, S., 2013. Design for Sensorless Force Control of Flexible Robot by using Resonance Ratio Control Based on Coefficient Diagram Method, Automatika, 54(1), special issue, selected papers from AMC2012 Conference, DOI:10.7305/automatika.54-1.311.

7. Mamdani, E.H., 1974. Application of Fuzzy Logic Algorithms for Control of Simple Dynamic Plant, Proc Inst Elec Eng., 1585-1588.

8. Karasakal, O., Yeşil, E., Güzelkaya, M., Eksin, I., 2005. Implementation of a New Self-tuning Fuzzy PID Controller on PLC, Turkish Journal of Electrical Engineering \& Computer Sciences, 13 (2), 277-286.

9. Tang, K.S., Man, K.F., Chen, G., Kwong, S., 2001. An Optimal Fuzzy PID Controller,
Industrial Electronics, IEEE Transactions on 48(4), 757-765.

10. Carvajal, J., Chen, G., Ogmen, H., 2000. Fuzzy PID controller: Design, performance evaluation, and stability analysis, Information Sciences, 123(3-4), 249-270, DOI: 10.1016/S0020-0255(99)00127-9.

11. Aghaei , V.T., Onat, A., Eksin, I., Guzelkaya, M., 2015. Fuzzy PID Controller Design using Q-learning Algorithm with a Manipulated Reward Function, Control Conference (ECC), European, 2502-2507.

12. Godjevac, J., 1993. Comparison Between PID and Fuzzy Control, Internal Report R93.36I, Ecole Polytechnique Fédérale de Lausanne Département d'Informatique Laboratoire de Microinformatique.

13. Ali, O.A.M., Ali, A.Y., Sumait, B.S., 2015. Comparison between the Effects of Different Types of Membership Functions on Fuzzy Logic Controller Performance, International Journal of Emerging Engineering Research and Technology, 3(3), 76-83.

14. Can, M.S., Ozguven, O.F., 2016. Nötrosofik Üyelik Fonksiyonlu Bulanık Mantık Denetleyici ile Sabit Miknatıslı Doğru Akım Motor Milinin Dönüş Açısının Kontrolü, EEB2016 Elektrik-Elektronik ve Bilgisayar Sempozyumu

15. Wang, H., Smarandache, F., Zhang, Y.Q., Sunderraman, R., 2010. Single Valued Neutrosophic Sets, Multispace and Multistructure (4), 410-413.

16. Arora, M., Pandey, U.S., 2012. Generalization of Functional Dependencies in Total of Functional Dependencies in Total Neutrosophic Relation, IJCSI International Journal of Computer Science, Issues, 9(3), No 2.

17. El-Bardini, M., El-Nagar, A.M., 2014. Interval Type-2 Fuzzy PID Controller for Uncertain Nonlinear Inverted Pendulum System, ISA Transactions, 53(3), 732-743.

18. Nie, M., Tan, W.W., 2011. Stable Adaptive Fuzzy PD Plus PI Controller for Nonlinear Uncertain Systems, Fuzzy Sets and Systems, 179(1), 1-19

19. Wu, H.N., 2007. Robust H2 Fuzzy Output Feedback Control for Discrete-time Nonlinear 
Nötrosofik Üyelik Fonksiyonlu Bulanık Mantı-PID (NBMD-PID) ve Geleneksel Bulanık Mantık-PID (BMD-PID) Denetleyicinin Gerçek Zamanlı Karşılaştırılması

Systems with Parametric Uncertainties, International Journal of Approximate Reasoning, 46(1), 151-165. 